\title{
Rapid Neurological Recovery Post Thrombolysis: Mechanisms and Implications
}

\author{
Bejoy Machumpurath, Maya Reddy, Bernard Yan
}

Melbourne Brain Centre, Royal Melbourne Hospital, Melbourne, Australia.

Email: bejoy.m@gmail.com, reddymaya@gmail.com, bernard.yan@mh.org.au

Received November $12^{\text {th }}, 2012$; revised December $20^{\text {th }}, 2012$; accepted January $6^{\text {th }}, 2013$

\begin{abstract}
Intravenous thrombolysis improves long term functional outcomes in acute ischemic stroke. A select proportion of patients treated with thrombolysis experience rapid early neurological recovery, a powerful predictor of favourable long term outcomes. There is increased interest to augment early neurological recovery by endovascular therapy or by adjuvant intravenous thrombolytics. However, incomplete understanding of the physiological mechanisms of early recovery has hampered a unified approach to monitor and to triage patients for invasive therapy. This review aims to examine the current understanding and insights gained from recent studies concerning early recovery and to inform the design of future studies.
\end{abstract}

Keywords: Stroke; Tissue Plasminogen Activator; Thrombolysis; Recovery; Rapid Recovery; Clinical Predictors

\section{Introduction}

The introduction of thrombolysis with intravenous tissue plasminogen activator (IV tPA) as an integral part of stroke management has significantly improved stroke outcomes [1-5]. Various studies including the pivotal NINDS and ECASS trials have shown that IV tPA reduces long term disability and improves function $[1,2,4]$. A proportion of patients treated with IV tPA experience a phenomenon termed rapid neurological recovery [6-12]. It has been shown that early recovery correlates with a more favourable long term prognosis [6-13]. This article aims to review rapid neurological recovery and its underlying mechanism, patterns of recovery, prognostic predictors and clinical implications.

\section{Rapid Neurological Recovery: Definitions, Incidence and Outcome}

A subset of patients treated with IV tPA have a significant recovery, shedding a substantial component of their neurological deficit within 24 hours [6-12,14]. This phenomenon has been documented in a number of studies, and has been labelled under a wide array of names including "rapid neurological recovery", "early neurological improvement”, "major neurological improvement”, "dramatic recovery" and the "Lazarus phenomenon". Similarly, it has been defined in numerous ways, as outlined in the Table 1.

Despite the differing labels and definitions, the inci- dence and outcomes of rapid neurological recovery have been reported consistently across the literature. Studies showed that between $18 \%$ - 33\% of patients treated with IV tPA experienced some form of early recovery [6-9,11, 12,14]. Furthermore, patients with rapid neurological recovery have lower 30 day mortality and are far more likely to have a favourable functional outcome (modified Rankin Score of 0 or 1) at 3months than patients without early recovery [6-10,14]. Muresan et al. demonstrated that $68 \%$ of patients who show evidence of such early recovery experience a favourable 3-month outcome in comparison to $29 \%$ of those without early recovery [11].

\section{Mechanism of Action}

\subsection{Early Recovery as an Expression of Early Recanalization}

The principle of thrombolysis is based on reperfusion of the ischemic penumbra, the consequence of which is the arrest of infarct growth [15-17]. The prevailing theory states that thrombolysis mediates its action by recanalization, which in turn, is strongly associated with tissue reperfusion [18,19]. This is supported by imaging and angiographic studies demonstrating the correlation between recanalization with reduction in mortality and improved long term functional outcome [20-28]. The DEFUSE study demonstrated that in patients with an ischemic penumbra, $56 \%$ of those that showed evidence of early reperfusion had a favourable outcome [16]. 
Table 1. Various definitions of rapid recovery.

\begin{tabular}{|c|c|}
\hline Labels & Definitions \\
\hline Rapid Neurological Recovery & Drop in NIHSS by $50 \%$ or more within 24 hours [7] \\
\hline Dramatic Recovery & Drop in NIHSS by 10 points or more OR Drop of NIHSS to 3 points or less during infusion [14] \\
\hline Early Dramatic improvement & Drop in NIHSS by 10 points or more OR Drop of NIHSS to 2 points or less, within 24 hours [30] \\
\hline Major Neurological Improvement & Drop in NIHSS by 8 points or more OR NIHSS of 0 points at 24 hours [6] \\
\hline Major Neurological Recovery & Drop in NIHSS by 8 points or more OR NIHSS of 0 or 1 at 24 hours $[9,12]$ \\
\hline Dramatic Recovery & Drop of NIHSS to 2 points or less after infusion [31] \\
\hline Early Improvement & Drop of NIHSS to 4 points or less at 24 hours [8] \\
\hline
\end{tabular}

Conversely, in the cohort without early reperfusion only $19 \%$ showed a good functional outcome, a finding mirrored in numerous studies [31,32]. As recovery is strongly associated with vessel recanalization, it stands to reason that early recovery is likely a consequence of early recanalization.

\subsection{Early Recanalization Is Not the Entire Story}

However, recent research has cast doubts over the role of recanalization as the sole determinant of early recovery. Alexandrov et al. showed that of 73 patients that experienced early recanalization post thrombolysis, $37 \%$ showed no early improvement, and $23 \%$ had suboptimal outcomes at 3 months [33]. Similar discordance has been shown in intra-arterial and mechanical retrieval studies where despite early recanalization rates of $70 \%$ and $81 \%$ respectively, only $34 \%$ and $25 \%$ of patients experienced a good outcome $[34,35]$. This demonstrates that a proportion of patients with early recanalization do not have early recovery, suggesting that there are other factors at play. The literature provides two major hypotheses that perhaps give some explanation for the discrepancy: 1) despite early recanalization, there is a lack of perfusion downstream; and 2) despite early recanalization, early recovery is delayed due to "stunning".

Recanalization does not definitively imply effective reperfusion. In fact, there are numerous means in which recanalization of the primary arterial occlusive site can result in failure of distal reperfusion such as downstream embolization, blockage of microcirculation with nonreflow phenomenon, or rapid infarction before recanalization $[22,36,37]$. The latter concept warrants some mention as it has had the most examination in the literature. Rapid infarction implies the loss of salvageable ischaemic tissue at the time of recanalization, resulting in non-nutritional reperfusion [22,36]. It is believed that the persistence of collateral supply protects this area from rapid infarction and in doing so allows early recanalization to facilitate early recovery [22,38-40]. It follows that early recanalization without coordination of such factors will not manifest in effective reperfusion and subsequent early recovery or recovery at all.

Alexandrov et al. proposes that this lack of correlation between early recanalization and early recovery may be attributed to the "stunned brain" hypothesis [33]. This theory describes prolonged functional deficit despite reperfusion, due to transient "stunning" after ischaemic insult $[41,42]$. It has been suggested that the stunning itself may be caused by resolving oedema, reperfusion injury, or delayed improvement of microcirculation in ischemic tissues [43-45]. Proponents of this hypothesis cite the select patient set who despite recanalization have poor short outcomes, but in the long term have favourable functional gains [33].Thus despite early recanalization, the recovery which theoretically should be early, may be delayed.

\section{The Pattern of Recovery in Rapid Neurological Recovery}

A consistent "pattern of deficit recovery" [14] has been observed in patients with Middle Cerebral Artery (MCA) occlusions experiencing rapid neurological recovery post IV tPA. First raised in case reports [46], this phenomenon has been examined in very few studies. Felberg et al. [14] noted that patients experiencing marked improvement during IV tPA infusion recovered their deficits in the following order: 1) gaze preference, 2) sensation, 3) leg motor, 4) arm motor, 5) face motor, 6) aphasia and 7) dysarthria. It was also noted that deficits that tended to recover earlier tended to recover completely, or to a greater extent than other deficits [14]. In particular, aphasic and dysarthric deficits, if present, were either very late to improve, had only a partial response, or did not improve at all. This pattern was also observed by 
Mikulik et al. [47]. Although there were slight differences in deficits recorded, the Mikulik study also noted gaze preference as the deficit most likely to recover earliest, and aphasia among one of the last deficits to recover, if at all [47].

Felberg et al. proposes that a stepwise restoration of collateral blood flow during clot dissolution would likely explain this curious pattern [14]. This theory is supported by the fact that the deficits that recovered early are represented in regions abutting Anterior Cerebral Artery (ACA) and Posterior Cerebral Artery (PCA) territory, on the border of the ischaemic penumbra. An alternative theory suggests that the proximal region of the thrombus is lysed, and flow is restored directly to the perforators originating in the M1 segment of the MCA and the terminal Internal Carotid Artery (ICA). This in turn, reperfuses the internal capsule and thalamus, which may account for this peculiar pattern of recovery $[14,48]$. However, given the few studies within this area, it is difficult to make meaningful conclusions.

\section{Clinical Predictors}

The literature describes many prognostic predictors for good outcome post stroke [49]. Similarly, studies examining rapid neurological recovery have identified numerous clinical predictors of the phenomenon itself, including age, baseline National Institute of Health Stroke Scale (NIHSS) and admission glucose [6-11,14].

\subsection{Baseline NIHSS}

A low baseline NIHSS score has been shown to be a clinical predictor of rapid neurological recovery. Machumpurath et al. [7] showed that those with baseline NIHSS scores of less than 12 were three times more likely to have early recovery than their more severely affected counterparts. This has been mirrored in other trials $[8,12,50]$.

One mechanism explaining this finding centers on the view that the NIHSS score is a surrogate marker of clot burden [51]. Larger clots would intuitively be less likely to lyse with IV tPA. It follows then that patients presenting with a high NIHSS score and therefore a greater clot burden, would be less susceptible to thrombolysis.

\subsection{Age}

Advancing age is a key risk factor for stroke, and yet thrombolysis in this demographic is associated with poorer outcomes in comparison to the younger patient set [52-54]. IV tPA in the elderly population is associated with less functional gain, an increased risk of Intra-cerebral Haemorrhage (ICH) and a higher rate of mortality [52-54]. Of note, increasing age is also associated with a lower probability of rapid neurological recovery [8]. Dharmasoraja et al. revealed that those less than 70 years of age are twice as likely to experience rapid recovery [8]. Similar results have been reproduced by Brown, Blinzler, Boddu and Machumpurath [6,7,12,55]. This is an intuitive finding reflected in the wider literature regarding age and outcome post stroke.

\subsection{Admission Glucose}

Hyperglycaemia is a poor prognostic predictor for rapid neurological recovery $[7,11,12]$. Machumpurath et al. showed that patients with hyperglycaemia on admission were 2.8 times less likely to experience rapid neurological recovery than their normoglycemic counterparts, a finding that was mirrored in other trials [7,9,11]. In fact, hyperglycemia has been associated with not only lower recanalization rates, but lower rates of rapid neurological recovery despite recanalization [56]. Moreover, the deleterious effects of hyperglycemia on stroke outcome as a whole are well documented [2,9,57-60].

Numerous mechanisms have been proposed to explain these findings. Diabetics and patients presenting with hyperglycemia have elevated serum levels of plasminogen activator inhibitor type 1 (PAI-1), a rapid endogenous inhibitor of tPA implicated in lowering levels of active tPA [61-63]. It follows that elevated levels of PAI-1 have been shown to be predictive of not only poor response to thrombolysis and failure of clot lysis, but also worse long term outcomes [61-65]. Although not directly pertaining to thrombolysis, there are two other major mechanisms in the literature explaining this interaction. The first suggests that hyperglycemia itself exacerbates brain injury via intracellular acidosis and increased free radical production, which despite recanalization may render the ischemic penumbra unsalvageable [66]. The second hypothesizes that increased glucose levels are a reflection of stress response and cortisol activation and/or damage to areas involved in glucose regulation [57,67].

\subsection{Time to Treatment}

Time to treatment is a surprising anomaly. While the fundamental NINDS trial showed the efficacy of thrombolysis to be within three hours of symptom onset, further research has demonstrated a favourable outcome in the 3 - 4.5 hour time window [1,2]. However, it remains that a shorter time to treatment is still associated with better long term outcomes. Lees et al. in their pooled analysis of the ECASS III and EPITHET trials showed that the a favourable three month outcome was inversely proportional to time to treatment with the odds ratio decreasing from 2.55 for $0-90 \mathrm{~min}$ to 1.22 for $271-360$ min [68]. While the impact of this predictor is well 
documented for 3-month outcomes, the effect of time to treatment on rapid neurological recovery has been consistently inconclusive with a large number of studies showing no significant association [6,7,9,11,12,50]. The literature has yet to propose a convincing explanation.

\subsection{Atrial Fibrillation}

It is well known that atrial fibrillation (AF) is associated with poor prognostic outcome in stroke [69,70]. Studies have shown that thrombolysis in this patient set is associated with poorer long term outcomes [71]. However, studies examining the influence of AF on early recovery post thrombolysis show mixed results. Kimura et al. suggests that AF significantly reduces the likelihood of early recanalization which in turn is associated with poor early recovery [72]. Similarly Blinzler and Dharmasaroja showed that early neurological recovery is more likely in patients without AF $[8,55]$. While such findings are significant, other studies have shown no correlation between AF and early recovery, emphasizing the need for further examination before any conclusions can be made $[6,7$, 9-11,73].

\section{Implications of Rapid Neurological Recovery}

Rapid neurological recovery post IV tPA is associated with improved long term outcomes. This has several implications regarding monitoring recovery and adjunctive therapies.

\subsection{Cost of Monitoring}

The level of disability and likelihood of functional dependence emphasize the significant cost of non-recovery to the individual. A study by Hong and Saver showed that in patients who benefit from thrombolytic intervention there is an associated 4.4 years gain in disability adjusted life years [74]. Examining the cost effectiveness of thrombolysis, Fagan et al. showed that while thrombolysis increased hospitalization costs by 1.7 million per 1000 , it reduces rehabilitation and nursing home costs by 1.4 million and 4.8 million respectively [75].

Although the benefit to patients and the community is not in question, the economic burden is still significant, and innovations to reduce the cost of thrombolytic therapy are welcome. One facet of this economic burden is the cost of monitoring during and post thrombolysis. The NIHSS score, the current gold standard for measuring stroke related deficit, involves measuring 15 different components of neurological dysfunction. While undoubtedly effective, monitoring by NIHSS requires a clinician trained in assessment, over numerous time periods pre and post administration of thrombolytic. It has been suggested that automated continuous monitoring of function, in particular motor recovery, can provide a similar measure of outcome with vastly reduced costs [76-78]. Devices such as accelerometers have been shown to be a reliable method of monitoring not only upper and lower limb motor function but also motor hemi-neglect and the integrity of the corticospinal tract [78-80]. In acute stroke these measures have shown moderate to strong correlations with gold standard scores such as NIHSS and the Fugal Meyer assessment arm section [81]. However studies have shown that this correlation disappears with three month outcome scores such as the modified Rankin scale and Barthel Index [82]. Nonetheless, continuous motor measurements have been shown to be reliable in measuring improvement of function in the subacute phase of recovery [78]. This can thus be a valuable tool as unlike current measures it allows direct comparison of acute and subacute functional gains while requiring less skilled clinician assessment.

\subsection{Adjunctive Therapies and Therapeutic Implications}

Rapid neurological recovery predicting favourable outcome has numerous clinical and therapeutic implications, one of which is improved patient selection. This would allow the proportion of patients least likely to respond to IV tPA to be treated with one of many more aggressive therapies. This has been an area of considerable study, looking at different intravenous agents and endovascular intervention.

Tenecteplase (TNK) is being presently studied as an alternative to standard IV tPA for acute ischemic stroke [83]. Initially explored in animal models [84,85], TNK is now validated for use in intravenous thrombolysis for myocardial infarction [86-88]. In fact, clinical pilot studies have demonstrated that TNK efficacy is comparable with tPA in acute ischemic stroke [89]. A promising development, TNK still awaits investigation by a large randomised control trial [83].

Other alternatives with greater evidence for practice include endovascular therapies. Intra-arterial (IA) thrombolysis has been shown to result in higher rates of recanalization when compared with IV tPA studies, but reduced morbidity and mortality at three months only when compared with placebo [90-93]. Indeed, there is no robust evidence of the benefit of endovascular procedures over conventional IV tPA treatment, and as such it is not approved for direct use in patients eligible for IV tPA [94-97]. However select non-responders, that is, patients that fail to respond with IV tPA, are subsequently offered IA "rescue therapy". This has shown considerable promise. Rubiera et al. showed that $40 \%$ of non-responders that received "rescue therapy" were func- 
tionally independent at 3 months as compared with only $14.9 \%$ of non-responders that were not offered any further therapy [97]. Nonetheless, these therapies have yet to be fully investigated. In particular, the optimal dose for IA therapy is yet to be validated, and there has not been a large randomised study directly comparing IV vs IA thrombolysis [98-100].

Rapid neurological recovery, within the context of these emerging therapies, has implications on treatment. Intravenous tPA is a validated therapy for acute ischemic stroke, and rapid neurological recovery represents the subset with the greatest positive response. Patient selection using the clinical predictors of rapid neurological recovery would permit identification of patients with the greatest potential for benefit from IV tPA. Conversely, the patients least likely to respond to conventional IV tPA (non-responders) could then be treated with more aggressive adjunctive therapies as a first line before they needed "rescuing", potentially leading to enhanced outcomes.

Lastly, this concept of patient selection could perhaps be extended further. Intravenous tPA is not a therapy without adverse effects (clinically significant side effects include intracerebral haemorrhage, systemic haemorrhage, re-occlusion and anaphylaxis). If further research were to focus on predictors of early recovery to accurately delineate the patient group of non-responders, such patients who stand to have the least benefit need not be exposed to the risks of therapy.

\section{Conclusion}

There is good evidence that rapid neurological recovery correlates with improved long term outcomes in ischemic stroke. Recanalization, in addition to advanced age, hyperglycaemia and high NIHSS, is an important determinant of recovery and a therapeutic target. However, it remains that a significant proportion of patients fail to demonstrate early recovery in spite of successful recanalization post thrombolysis, raising reasonable doubts on our current understanding of its underlying mechanism. Future studies should focus on the elucidation of the pathophysiology of rapid neurological recovery and recanalization.

\section{REFERENCES}

[1] W. Hacke, M. Kaste, E. Bluhmki, M. Brozman, A. Davalos, D. Guidetti, et al., "Thrombolysis with Alteplase 3 to 4.5 Hours after Acute Ischemic Stroke,” The New England Journal of Medicine, Vol. 359, No. 13, 2008, pp. 1317-1329. doi:10.1056/NEJMoa0804656

[2] The National Institute of Neurological Disorders and Stroke rt-PA Stroke Study Group, “Tissue Plasminogen Activator for Acute Ischemic Stroke,” The New England Journal of Medicine, Vol. 333, No. 24, 1995, pp. 1581-
1587. doi:10.1056/NEJM199512143332401

[3] N. Wahlgren, N. Ahmed, A. Davalos, G. A. Ford, M. Grond, W. Hacke, et al., "Thrombolysis with Alteplase for Acute Ischaemic Stroke in the Safe Implementation of Thrombolysis in Stroke-Monitoring Study (SITS-MOST): An Observational Study," Lancet, Vol. 369, No. 9558, 2007, pp. 275-282. doi:10.1016/S0140-6736(07)60149-4

[4] W. Hacke, M. Kaste, C. Fieschi, R. von Kummer, A. Davalos, D. Meier, et al., "Randomised Double-Blind Placebo-Controlled Trial of Thrombolytic Therapy with Intravenous Alteplase in Acute Ischaemic Stroke (ECASS II). Second European-Australasian Acute Stroke Study Investigators," Lancet, Vol. 352, No. 9136, 1998, pp. 1245-1251. doi:10.1016/S0140-6736(98)08020-9

[5] P. Sandercock, J. M. Wardlaw, R. I. Lindley, M. Dennis, G. Cohen, G. Murray, et al., "The Benefits and Harms of Intravenous Thrombolysis with Recombinant Tissue Plasminogen Activator within $6 \mathrm{~h}$ of Acute Ischaemic Stroke (the Third International Stroke Trial [IST-3]): A Randomised Controlled Trial," Lancet, Vol. 379, No. 9834, 2012, pp. 2352-2363. doi:10.1016/S0140-6736(12)60768-5

[6] D. L. Brown, K. C. Johnston, D. P. Wagner and E. C. Haley Jr., "Predicting Major Neurological Improvement with Intravenous Recombinant Tissue Plasminogen Activator Treatment of Stroke,” Stroke, Vol. 35, No. 1, 2004, pp. 147-150. doi:10.1161/01.STR.0000105396.93273.72

[7] B. Machumpurath, S. M. Davis and B. Yan, "Rapid Neurological Recovery after Intravenous Tissue Plasminogen Activator in Stroke: Prognostic Factors and Outcome," Cerebrovascular Disease, Vol. 31, No. 3, 2010, pp. 278283. doi:10.1159/000322564

[8] P. A. Dharmasaroja, S. Muengtaweepongsa and P. Dharmasaroja, "Early Outcome after Intravenous Thrombolysis in Patients with Acute Ischemic Stroke," Neurology India, Vol. 59, No. 3, 2011, pp. 351-354. doi:10.4103/0028-3886.82723

[9] G. Saposnik, S. Di Legge, F. Webster and V. Hachinski, "Predictors of Major Neurologic Improvement after Thrombolysis in Acute Stroke,” Neurology, Vol. 65, No. 8, 2005, pp. 1169-1174. doi:10.1212/01.wnl.0000180687.75907.4b

[10] T. Kharitonova, R. Mikulik, R. O. Roine, L. Soinne, N. Ahmed and N. Wahlgren, "Association of Early National Institutes of Health Stroke Scale Improvement with Vessel Recanalization and Functional Outcome after Intravenous Thrombolysis in Ischemic Stroke,” Stroke, Vol. 42, No. 6, 2011, pp. 1638-1643. doi:10.1161/STROKEAHA.110.606194

[11] I. P. Muresan, P. Favrole, P. Levy, F. Andreux, B. Marro and S. Alamowitch, "Very Early Neurologic Improvement after Intravenous Thrombolysis," Archives of Neurology, Vol. 67, No. 11, 2010, pp. 1323-1328. doi:10.1001/archneurol.2010.265

[12] D. B. Boddu, V. C. Srinivasarao Bandaru, P. G. Reddy, M. Madhusudan, M. K. Rukmini, T. Suryaprabha, et al., "Predictors of Major Neurological Improvement after Intravenous Thrombolysis in Acute Ischemic Stroke: A Hospital-Based Study from South India,” Neurology In- 
dia, Vol. 58, No. 3, 2010, pp. 403-406. doi:10.4103/0028-3886.66085

[13] H. S. Nam, K. Y. Lee, S. W. Han, S. H. Kim, J. Y. Lee, S. H. Ahn, et al., "Prediction of Long-Term Outcome by Percent Improvement after the First Day of Thrombolytic Treatment in Stroke Patients," Journal of the Neurological Sciences, Vol. 281, No. 1-2, 2009, pp. 69-73. doi:10.1016/j.jns.2009.02.365

[14] R. A. Felberg, N. J. Okon, A. El-Mitwalli, W. S. Burgin, J. C. Grotta and A. V. Alexandrov, "Early Dramatic Recovery during Intravenous Tissue Plasminogen Activator Infusion: Clinical Pattern and Outcome in Acute Middle Cerebral Artery Stroke," Stroke, Vol. 33, No. 5, 2002, pp. 1301-1307. doi:10.1161/01.STR.0000015556.48283.74

[15] S. M. Davis, G. A. Donnan, M. W. Parsons, C. Levi, K. S. Butcher, A. Peeters, et al. "Effects of Alteplase beyond 3 $\mathrm{h}$ after Stroke in the Echoplanar Imaging Thrombolytic Evaluation Trial (EPITHET): A Placebo-Controlled Randomised Trial," Lancet Neurology, Vol. 7, No. 4, 2008, pp. 299-309. doi:10.1016/S1474-4422(08)70044-9

[16] G. W. Albers, V. N. Thijs, L. Wechsler, S. Kemp, G. Schlaug, E. Skalabrin, et al., "Magnetic Resonance Imaging Profiles Predict Clinical Response to Early Reperfusion: The Diffusion and Perfusion Imaging Evaluation for Understanding Stroke Evolution (DEFUSE) Study," Annals of Neurology, Vol. 60, No. 5, 2006, pp. 508-517. doi:10.1002/ana.20976

[17] A. R. Young, O. Touzani, J. M. Derlon, G. Sette, E. T. MacKenzie and J. C. Baron, "Early Reperfusion in the Anesthetized Baboon Reduces Brain Damage Following Middle Cerebral Artery Occlusion: A Quantitative Analysis of Infarction Volume,” Stroke, Vol. 28, No. 3, 1997, pp. 632-637. doi:10.1161/01.STR.28.3.632

[18] D. A. De Silva, J. N. Fink, S. Christensen, M. Ebinger, C. Bladin, C. R. Levi, et al., "Assessing Reperfusion and Recanalization as Markers of Clinical Outcomes after Intravenous Thrombolysis in the Echoplanar Imaging Thrombolytic Evaluation Trial (EPITHET),” Stroke, Vol. 40, No. 8, 2009, pp. 2872-2874. doi:10.1161/STROKEAHA.108.543595

[19] W. D. Heiss, M. Grond, A. Thiel, H. M. von Stockhausen, J. Rudolf, M. Ghaemi, et al., "Tissue at Risk of Infarction Rescued by Early Reperfusion: A Positron Emission Tomography Study in Systemic Recombinant Tissue Plasminogen Activator Thrombolysis of Acute Stroke,” Journal of Cerebral Blood Flow \& Metabolism, Vol. 18, No. 12, 1998, pp. 1298-1307. doi:10.1097/00004647-199812000-00004

[20] L. A. Labiche, M. Malkoff and A. V. Alexandrov, "Residual Flow Signals Predict Complete Recanalization in Stroke Patients Treated with TPA," Journal of Neuroimaging, Vol. 13, No. 1, 2003, pp. 28-33.

[21] M. T. Wunderlich, M. Goertler, T. Postert, E. Schmitt, G. Seidel, G. Gahn, et al., "Recanalization after Intravenous Thrombolysis: Does a Recanalization Time Window Exist?” Neurology, Vol. 68, No. 17, 2007, pp. 1364-1368. doi:10.1212/01.wnl.0000260604.26469.8e

[22] J. H. Rha and J. L. Saver, "The Impact of Recanalization on Ischemic Stroke Outcome: A Meta-Analysis,” Stroke,
Vol. 38, No. 3, 2007, pp. 967-973. doi:10.1161/01.STR.0000258112.14918.24

[23] E. Mori, Y. Yoneda, M. Tabuchi, T. Yoshida, S. Ohkawa, Y. Ohsumi, et al., "Intravenous Recombinant Tissue Plasminogen Activator in Acute Carotid Artery Territory Stroke,” Neurology, Vol. 42, No. 5, 1992, pp. 976-982. doi:10.1212/WNL.42.5.976

[24] G. J. del Zoppo and J. A. Koziol, "Recanalization and Stroke Outcome,” Circulation, Vol. 115, No. 20, 2007, pp. 2602-2605. doi:10.1161/CIRCULATIONAHA.107.698225

[25] T. Neumann-Haefelin, R. du Mesnil de Rochemont, J. B. Fiebach, A. Gass, C. Nolte, T. Kucinski, et al., "Effect of Incomplete (Spontaneous and Postthrombolytic) Recanalization after Middle Cerebral Artery Occlusion: A Magnetic Resonance Imaging Study,” Stroke, Vol. 35, No. 1, 2004, pp. 109-114. doi:10.1161/01.STR.0000106482.31425.D1

[26] R. Bhatia, M. D. Hill, N. Shobha, B. Menon, S. Bal, P. Kochar, et al., "Low Rates of Acute Recanalization with Intravenous Recombinant Tissue Plasminogen Activator in Ischemic Stroke: Real-World Experience and a Call for Action,” Stroke, Vol. 41, No. 10, 2010, pp. 2254-2258. doi:10.1161/STROKEAHA.110.592535

[27] L. A. Labiche, F. Al-Senani, A. W. Wojner, J C. Grotta, M. Malkoff and A. V. Alexandrov, "Is the Benefit of Early Recanalization Sustained at 3 Months? A Prospective Cohort Study,” Stroke, Vol. 34, No. 3, 2003, pp. 695698. doi:10.1161/01.STR.0000055940.00316.6B

[28] I. Christou, A. V. Alexandrov, W. S. Burgin, A. W. Wojner, R. A. Felberg, M. Malkoff, et al., "Timing of Recanalization after Tissue Plasminogen Activator Therapy Determined by Transcranial Doppler Correlates with Clinical Recovery from Ischemic Stroke,” Stroke, Vol. 31, No. 8, 2000, pp. 1812-1816. doi:10.1161/01.STR.31.8.1812

[29] G. A. Christofordis, Y. Mohammad, M. Yang, C. Louis, A. Slivka, et al., "Factors Associated with a 'Lazarus Phenomenon' 24 Hours Following Intraarterial Thrombolytic Therapy in Acute Ischemic Stroke,” International Stroke Conference, San Francisco, 7-9 February 2007.

[30] H. Kawano, T. Hirano, Y. Inatomi, T. Terasaki, T. Yonehara and M. Uchino, "Presence of Deep White Matter Lesions on Diffusion-Weighted Imaging Is a Negative Predictor of Early Dramatic Improvement after Intravenous Tissue Plasminogen Activator Thrombolysis," Cerebrovascular Disease, Vol. 30, No. 3, 2010, pp. 230-236. doi:10.1159/000317183

[31] A. V. Alexandrov, R. A. Felberg, A. M. Demchuk, I. Christou, W. S. Burgin, M. Malkoff, et al., "Deterioration Following Spontaneous Improvement: Sonographic Findings in Patients with Acutely Resolving Symptoms of Cerebral Ischemia," Stroke, Vol. 31, No. 4, 2000, pp. 915-919. doi:10.1161/01.STR.31.4.915

[32] V. Rajajee, C. Kidwell, S. Starkman, B. Ovbiagele, J. R. Alger, P. Villablanca, et al., "Early MRI and Outcomes of Untreated Patients with Mild or Improving Ischemic Stroke,” Neurology, Vol. 67, No. 6, 2006, pp. 980-984. doi:10.1212/01.wnl.0000237520.88777.71 
[33] A. V. Alexandrov, C. E. Hall, L. A. Labiche, A. W. Wojner and J. C. Grotta, "Ischemic Stunning of the Brain: Early Recanalization without Immediate Clinical Improvement in Acute Ischemic Stroke,” Stroke, Vol. 35, No. 2, 2004, pp. 449-452. doi:10.1161/01.STR.0000113737.58014.B4

[34] W. S. Smith, G. Sung, J. Saver, R. Budzik, G. Duckwiler, D. S. Liebeskind, et al., "Mechanical Thrombectomy for Acute Ischemic Stroke: Final Results of the Multi MERCI Trial,” Stroke, Vol. 39, No. 4, 2008, pp. 1205-1212. doi:10.1161/STROKEAHA.107.497115

[35] The Penumbra Pivotal Stroke Trial Investigators, "The Penumbra Pivotal Stroke Trial: Safety and Effectiveness of a New Generation of Mechanical Devices for Clot Removal in Intracranial Large Vessel Occlusive Disease,” Stroke, Vol. 40, No. 8, 2009, pp. 2761-2768. doi:10.1161/STROKEAHA.108.544957

[36] C. A. Molina and J. Alvarez-Sabin, "Recanalization and Reperfusion Therapies for Acute Ischemic Stroke,” Cerebrovascular Disease, Vol. 27, No. 1, 2009, pp. 162-167. doi:10.1159/000200455

[37] P. Khatri, J. Neff, J. P. Broderick, J. C. Khoury, J. Carrozzella and T. Tomsick, "Revascularization End Points in Stroke Interventional Trials: Recanalization versus Reperfusion in IMS-I,” Stroke, Vol. 36, No. 11, 2005, pp. 2400-2403. doi:10.1161/01.STR.0000185698.45720.58

[38] G. A. Christoforidis, Y. Mohammad, D. Kehagias, B. Avutu and A. P. Slivka, "Angiographic Assessment of Pial Collaterals as a Prognostic Indicator Following IntraArterial Thrombolysis for Acute Ischemic Stroke,” American Journal of Neuroradiology, Vol. 26, No. 7, 2005, pp. 1789-1797.

[39] D. S. Liebeskind, D. Kim, S. Starkman, K. Changizi, A. G. Ohanian, R. Jahan, et al., "Collateral Failure? Late Mechanical Thrombectomy after Failed Intravenous Thrombolysis,” Journal of Neuroimaging, Vol. 20, No. 1, 2008, pp. 78-82. doi:10.1111/j.1552-6569.2008.00295.X

[40] M. G. Lansberg, M. Straka, S. Kemp, M. Mlynash, L. R. Wechsler, T. G. Jovin, et al., "MRI Profile and Response to Endovascular Reperfusion after Stroke (DEFUSE 2): A Prospective Cohort Study,” Lancet Neurology, Vol. 11, No. 10, 2012, pp. 860-867. doi:10.1016/S1474-4422(12)70203-X

[41] R. Bolli and E. Marban, "Molecular and Cellular Mechanisms of Myocardial Stunning," Physiological Reviews, Vol. 79, No. 2, 1999, pp. 609-634.

[42] H. Luss, M. Schafers, J. Neumann, D. Hammel, C. Vahlhaus, H. A. Baba, et al., "Biochemical Mechanisms of Hibernation and Stunning in the Human Heart," Cardiovascular Research, Vol. 56, No. 3, 2002, pp. 411-421. doi:10.1016/S0008-6363(02)00596-5

[43] R. von Kummer, H. Bourquain, S. Bastianello, L. Bozzao, C. Manelfe, D. Meier, et al., "Early Prediction of Irreversible Brain Damage after Ischemic Stroke at CT," Radiology, Vol. 219, No. 1, 2001, pp. 95-100.

[44] D. Uematsu, J. H. Greenberg, M. Reivich and W. F. Hickey, "Direct Evidence for Calcium-Induced Ischemic and Reperfusion Injury,” Annals of Neurology, Vol. 26, No. 2, 1989, pp. 280-283. doi:10.1002/ana.410260217
[45] M. Hallett, "Functional Reorganization after Lesions of the Human Brain: Studies with Transcranial Magnetic Stimulation," Revue Neurologique Société de Neurologie de Paris, Vol. 157, No. 8-9, 2001, pp. 822-826.

[46] K. Minematsu, T. Yamaguchi and T. Omae, “"Spectacular Shrinking Deficit': Rapid Recovery from a Major Hemispheric Syndrome by Migration of an Embolus,” Neurology, Vol. 42, No. 1, 1992, pp. 157-162. doi:10.1212/WNL.42.1.157

[47] R. Mikulik, L. Dusek, M. D. Hill, E. Fulep, J. C. Grotta, M. Ribo, et al., "Pattern of Response of National Institutes of Health Stroke Scale Components to Early Recanalization in the CLOTBUST Trial," Stroke, Vol. 41, No. 3, 2010, pp. 466-470. doi:10.1161/STROKEAHA.109.567263

[48] L. Tatu, T. Moulin, J. Bogousslavsky and H. Duvernoy, "Arterial Territories of the Human Brain: Cerebral Hemispheres,” Neurology, Vol. 50, No. 6, 1998, pp. 1699-1708. doi:10.1212/WNL.50.6.1699

[49] A. M. Demchuk and A. M. Buchan, "Predictors of Stroke Outcome,” Neurologic Clinics, Vol. 18, No. 2, 2000, pp. 455-473. doi:10.1016/S0733-8619(05)70202-4

[50] D. Strbian, T. Sairanen, K. Rantanen, K. Piironen, S. Atula, T. Tatlisumak, et al., "Characteristics and Outcome of Ischemic Stroke Patients Who Are Free of Symptoms at 24 Hours Following Thrombolysis," Cerebrovascular Disease, Vol. 31, No. 1, 2010, pp. 37-42. doi:10.1159/000320263

[51] U. Fischer, M. Arnold, K. Nedeltchev, C. Brekenfeld, P. Ballinari, L. Remonda, et al., "NIHSS Score and Arteriographic Findings in Acute Ischemic Stroke,” Stroke, Vol. 36, No. 10, 2005, pp. 2121-2125. doi:10.1161/01.STR.0000182099.04994.fC

[52] J. Berrouschot, J. Rother, J. Glahn, T. Kucinski, J. Fiehler and G. Thomalla, "Outcome and Severe Hemorrhagic Complications of Intravenous Thrombolysis with Tissue Plasminogen Activator in Very Old ( $>$ or $=80$ Years) Stroke Patients,” Stroke, Vol. 36, No. 11, 2005, pp. 24212425. doi:10.1161/01.STR.0000185696.73938.e0

[53] D. Toni, S. Lorenzano, G. Agnelli, D. Guidetti, G. Orlandi, A. Semplicini, et al., "Intravenous Thrombolysis with rt-PA in Acute Ischemic Stroke Patients Aged Older than 80 Years in Italy,” Cerebrovascular Disease, Vol. 25, No. 1-2, 2008, pp. 129-135. doi:10.1159/000112323

[54] N. K. Mishra, N. Ahmed, G. Andersen, J. A. Egido, P. J. Lindsberg, P. A. Ringleb, et al., "Thrombolysis in Very Elderly People: Controlled Comparison of SITS International Stroke Thrombolysis Registry and Virtual International Stroke Trials Archive,” British Medical Journal, Vol. 341, 2010, c6046. doi:10.1136/bmj.c6046

[55] C. Blinzler, L. Breuer, H. B. Huttner, P. D. Schellinger, S. Schwab and M. Kohrmann, "Characteristics and Outcome of Patients with Early Complete Neurological Recovery after Thrombolysis for Acute Ischemic Stroke,” Cerebrovascular Disease, Vol. 31, No. 2, 2010, pp. 185-190. doi:10.1159/000321869

[56] J. Alvarez-Sabin, C. A. Molina, J. Montaner, J. F. Arenillas, R. Huertas, M. Ribo, et al., "Effects of Admission 
Hyperglycemia on Stroke Outcome in Reperfused Tissue Plasminogen Activator-Treated Patients," Stroke, Vol. 34, No. 5, 2003, pp. 1235-1241. doi:10.1161/01.STR.0000068406.30514.31

[57] A. Y. Poppe, S. R. Majumdar, T. Jeerakathil, W. Ghali, A. M. Buchan and M. D. Hill, "Admission Hyperglycemia Predicts a Worse Outcome in Stroke Patients Treated with Intravenous Thrombolysis," Diabetes Care, Vol. 32, No. 4, 2009, pp. 617-622. doi:10.2337/dc08-1754

[58] J. Putaala, T. Sairanen, A. Meretoja, P. J. Lindsberg, M. Tiainen, R. Liebkind, et al., "Post-Thrombolytic Hyperglycemia and 3-Month Outcome in Acute Ischemic Stroke,” Cerebrovascular Disease, Vol. 31, No. 1, 2010, pp. 83-92. doi:10.1159/000321332

[59] S. E. Capes, D. Hunt, K. Malmberg, P. Pathak and H. C. Gerstein, "Stress Hyperglycemia and Prognosis of Stroke in Nondiabetic and Diabetic Patients: A Systematic Overview,” Stroke, Vol. 32, No. 10, 2001, pp. 2426-2432. doi:10.1161/hs1001.096194

[60] A. Y. Poppe and M. D. Hill, "Hyperglycemia in Thrombolysed Acute Ischemic Stroke Patients," International Journal of Stroke, Vol. 6, No. 3, 2011, p. 278.

[61] K. Huber, "Plasminogen Activator Inhibitor Type-1 (Part One): Basic Mechanisms, Regulation, and Role for Thromboembolic Disease," Journal of Thrombosis and Thrombolysis, Vol. 11, No. 3, 2001, pp. 183-193. doi:10.1023/A:1011955018052

[62] K. Huber, "Plasminogen Activator Inhibitor Type-1 (Part Two): Role for Failure of Thrombolytic Therapy. PAI-1 Resistance as a Potential Benefit for New Fibrinolytic Agents," Journal of Thrombosis and Thrombolysis, Vol. 11, No. 3, 2001, pp. 195-202. doi:10.1023/A:1011952602122

[63] S. C. Nicholls, E. K. Hoffer and W. L. Chandler, "Failure of Peripheral Arterial Thrombolysis Due to Elevated Plasminogen Activator Inhibitor Type 1,” Blood Coagulation \& Fibrinolysis, Vol. 14, No. 8, 2003, pp. 729-733. doi:10.1097/00001721-200312000-00006

[64] D. J. Schneider, T. K. Nordt and B. E. Sobel, “Attenuated Fibrinolysis and Accelerated Atherogenesis in Type II Diabetic Patients,” Diabetes, Vol. 42, No. 1, 1993, pp. 17. doi:10.2337/diabetes.42.1.1

[65] Y. Zhu, P. Carmeliet and W. P. Fay, "Plasminogen Activator Inhibitor-1 Is a Major Determinant of Arterial Thrombolysis Resistance," Circulation, Vol. 99, No. 23, 1999, pp. 3050-3055. doi:10.1161/01.CIR.99.23.3050

[66] W. D. Dietrich, O. Alonso and R. Busto, "Moderate Hyperglycemia Worsens Acute Blood-Brain Barrier Injury after Forebrain Ischemia in Rats,” Stroke, Vol. 24, No. 1, 1993, pp. 111-116. doi:10.1161/01.STR.24.1.111

[67] L. E. Allport, K. S. Butcher, T. A. Baird, L. MacGregor, P. M. Desmond, B. M. Tress, et al., "Insular Cortical Ischemia Is Independently Associated with Acute Stress Hyperglycemia,” Stroke, Vol. 35, No. 8, 2004, pp. 18861891. doi:10.1161/01.STR.0000133687.33868.71

[68] K. R. Lees, E. Bluhmki, R. von Kummer, T. G. Brott, D. Toni, J. C. Grotta, et al., "Time to Treatment with Intravenous Alteplase and Outcome in Stroke: An Updated Pooled Analysis of ECASS, ATLANTIS, NINDS, and
EPITHET Trials,” Lancet, Vol. 375, No. 9727, 2010, pp. 1695-1703. doi:10.1016/S0140-6736(10)60491-6

[69] K. Kimura, K. Minematsu and T. Yamaguchi, "Atrial Fibrillation as a Predictive Factor for Severe Stroke and Early Death in 15,831 Patients with Acute Ischaemic Stroke,” Journal of Neurology, Neurosurgery \& Psychiatry, Vol. 76, No. 5, 2005, pp. 679-683. doi:10.1136/jnnp.2004.048827

[70] G. D. Lowe, A. J. Jaap and C. D. Forbes, "Relation of Atrial Fibrillation and High Haematocrit to Mortality in Acute Stroke,” Lancet, Vol. 1, No. 8328, 1983, pp. 784786. doi:10.1016/S0140-6736(83)91848-2

[71] K. Kimura, Y. Iguchi, K. Shibazaki, T. Iwanaga, S. Yamashita and J. Aoki, "IV t-PA Therapy in Acute Stroke Patients with Atrial Fibrillation," Journal of the Neurological Sciences, Vol. 276, No. 1-2, 2009, pp. 6-8. doi:10.1016/j.jns.2008.10.018

[72] K. Kimura, Y. Iguchi, S. Yamashita, K. Shibazaki, K. Kobayashi and T. Inoue, "Atrial Fibrillation as an Independent Predictor for No Early Recanalization after IV-t-PA in Acute Ischemic Stroke,” Journal of the Neurological Sciences, Vol. 267, No. 1-2, 2008, pp. 57-61. doi:10.1016/j.jns.2007.09.036

[73] D. Sanak, R. Herzig, M. Kral, A. Bartkova, J. Zapletalova, M. Hutyra, et al., "Is Atrial Fibrillation Associated with Poor Outcome after Thrombolysis?” Journal of Neurology, Vol. 257, No. 6, 2010, pp. 999-1003. doi:10.1007/s00415-010-5452-4

[74] K. S. Hong and J. L. Saver, "Years of Disability-Adjusted Life Gained as a Result of Thrombolytic Therapy for Acute Ischemic Stroke," Stroke, Vol. 41, No. 3, 2010, pp. 471-477. doi:10.1161/STROKEAHA.109.571083

[75] S. C. Fagan, "Stroke: Measuring Disease-Free Life after Thrombolysis,” Nature Reviews Neurology, Vol. 6, No. 7, 2010, pp. 361-362. doi:10.1038/nrneurol.2010.79

[76] S. Patel, R. Hughes, T. Hester, J. Stein, M. Akay, J. Dy, et al., "Tracking Motor Recovery in Stroke Survivors Undergoing Rehabilitation Using Wearable Technology," Conference Proceedings of IEEE Engineering in Medicine and Biology Society, Vol. 2010, 2010, pp. 68586861.

[77] A. Parnandi, E. Wade and M. Mataric, "Motor Function Assessment Using Wearable Inertial Sensors,” Conference Proceedings of IEEE Engineering in Medicine and Biology Society, Vol. 2010, 2010, pp. 86-89.

[78] N. Gebruers C. Vanroy, S. Truijen, S. Engelborghs and P. P. De Deyn, "Monitoring of Physical Activity after Stroke: A Systematic Review of Accelerometry-Based Measures," Archives of Physical Medicine and Rehabilitation, Vol. 91, No. 2, 2010, pp. 288-297. doi:10.1016/j.apmr.2009.10.025

[79] E. M. Siekierka-Kleiser, R. Kleiser, A. M. Wohlschlager, H. J. Freund and R. J. Seitz, "Quantitative Assessment of Recovery from Motor Hemineglect in Acute Stroke Patients," Cerebrovascular Disease, Vol. 21, No. 5-6, 2006, pp. 307-214. doi:10.1159/000091535

[80] C. Calautti, P. S. Jones, N. Persaud, J. Y. Guincestre, M. Naccarato, E. A. Warburton, et al., "Quantification of Index Tapping Regularity after Stroke with Tri-Axial Ac- 
celerometry,” Brain Research Bulletin, Vol. 70, No. 1, 2006, pp. 1-7. doi:10.1016/j.brainresbull.2005.11.001

[81] N. Gebruers, S. Truijen, S. Engelborghs, G. Nagels, R. Brouns and P. P. De Deyn, "Actigraphic Measurement of Motor Deficits in Acute Ischemic Stroke," Cerebrovascular Disease, Vol. 26, No. 5, 2008, pp. 533-540. doi:10.1159/000160210

[82] V. Reiterer, C. Sauter, G. Klosch, W. Lalouschek and J. Zeitlhofer, "Actigraphy-A Useful Tool for Motor Activity Monitoring in Stroke Patients,” European Neurology, Vol. 60, No. 6, 2008, pp. 285-291. doi:10.1159/000157882

[83] P. Lyden, “Tenecteplase for Acute Ischemic Stroke,” International Journal of Stroke, Vol. 6, No. 6, 2011, pp. 509-510. doi:10.1111/j.1747-4949.2011.00695.x

[84] D. F. Chapman, P. Lyden, P. A. Lapchak, S. Nunez, H. Thibodeaux and J. Zivin, "Comparison of TNK with WildType Tissue Plasminogen Activator in a Rabbit Embolic Stroke Model," Stroke, Vol. 32, No. 3, 2001, pp. 748-752. doi:10.1161/01.STR.32.3.748

[85] P. A. Lapchak, D. M. Araujo and J. A. Zivin, "Comparison of Tenecteplase with Alteplase on Clinical Rating Scores Following Small Clot Embolic Strokes in Rabbits,” Experimental Neurology, Vol. 185, No. 1, 2004, pp. 154-159. doi:10.1016/j.expneurol.2003.09.009

[86] C. P. Cannon, C. H. McCabe, C. M. Gibson, M. Ghali, R. F. Sequeira, G. R. McKendall, et al., "TNK-Tissue Plasminogen Activator in Acute Myocardial Infarction. Results of the Thrombolysis in Myocardial Infarction (TIMI) 10A Dose-Ranging Trial," Circulation, Vol. 95, No. 2, 1997, pp. 351-356. doi:10.1161/01.CIR.95.2.351

[87] F. Van de Werf, C. P. Cannon, A. Luyten, K. Houbracken, C. H. McCabe, S. Berioli, et al., "Safety Assessment of Single-Bolus Administration of TNK Tissue-Plasminogen Activator in Acute Myocardial Infarction: The ASSENT1 Trial. The ASSENT-1 Investigators," American Heart Journal, Vol. 137, No. 5, 1999, pp. 786-791. doi:10.1016/S0002-8703(99)70400-X

[88] F. Van De Werf, J. Adgey, D. Ardissino, P. W. Armstrong, P. Aylward, G. Barbash, et al., "Single-Bolus Tenecteplase Compared with Front-Loaded Alteplase in Acute Myocardial Infarction: The ASSENT-2 DoubleBlind Randomised Trial,” Lancet, Vol. 354, No. 9180, 1999, pp. 716-722. doi:10.1016/S0140-6736(99)07403-6

[89] M. W. Parsons, F. Miteff, G. A. Bateman, N. Spratt, A. Loiselle, J. Attia, et al., "Acute Ischemic Stroke: Imaging-Guided Tenecteplase Treatment in an Extended Time Window,” Neurology, Vol. 72, No. 10, 2009, pp. 915-921. doi:10.1212/01.wnl.0000344168.05315.9d

[90] G. J. del Zoppo, A. Ferbert, S. Otis, H. Bruckmann, W. Hacke, J. Zyroff, et al., "Local Intra-Arterial Fibrinolytic Therapy in Acute Carotid Territory Stroke. A Pilot Study," Stroke, Vol. 19, No. 3, 1988, pp. 307-313. doi:10.1161/01.STR.19.3.307
[91] S. L. Barnwell, W. M. Clark, T. T. Nguyen, O. R. O’Neill, M. L. Wynn and B. M. Coull, "Safety and Efficacy of Delayed Intraarterial Urokinase Therapy with Mechanical Clot Disruption for Thromboembolic Stroke," American Journal of Neuroradiology, Vol. 15, No. 10, 1994, pp. 1817-1822.

[92] G. J. del Zoppo, R. T. Higashida, A. J. Furlan, M. S. Pessin, H. A. Rowley and M. Gent, "PROACT: A Phase II Randomized Trial of Recombinant Pro-Urokinase by Direct Arterial Delivery in Acute Middle Cerebral Artery Stroke. PROACT Investigators. Prolyse in Acute Cerebral Thromboembolism," Stroke, Vol. 29, No. 1, 1998, pp. 4-11. doi:10.1161/01.STR.29.1.4

[93] A. Furlan, R. Higashida, L. Wechsler, M. Gent, H. Rowley, C. Kase, et al., "Intra-Arterial Prourokinase for Acute Ischemic Stroke. The PROACT II Study: A Randomized Controlled Trial. Prolyse in Acute Cerebral Thromboembolism," Journal of the American Medical Association, Vol. 282, No. 21, 1999, pp. 2003-2011. doi:10.1001/jama.282.21.2003

[94] J. P. Broderick, "Endovascular Therapy for Acute Ischemic Stroke,” Stroke, Vol. 40, No. 3, 2009, pp. S103-S106. doi:10.1161/STROKEAHA.108.533067

[95] The IMS II Trial Investigators, "The Interventional Management of Stroke (IMS) II Study,” Stroke, Vol. 38, No. 7, 2007, pp. 2127-2135. doi:10.1161/STROKEAHA.107.483131

[96] J. D. Fields, K. Lindsay, K. C. Liu, G. M. Nesbit and H L. Lutsep, "Mechanical Thrombectomy for the Treatment of Acute Ischemic Stroke,” Expert Review of Cardiovascular Therapy, Vol. 8, No. 4, 2010, pp. 581-592. doi:10.1586/erc. 10.8

[97] M. Rubiera, M. Ribo, J. Pagola, P. Coscojuela, D. Rodriguez-Luna, O. Maisterra, et al., "Bridging IntravenousIntra-Arterial Rescue Strategy Increases Recanalization and the Likelihood of a Good Outcome in Nonresponder Intravenous Tissue Plasminogen Activator-Treated Patients: A Case-Control Study," Stroke, Vol. 42, No. 4, 2011, pp. 993-997. doi:10.1161/STROKEAHA.110.597104

[98] J. M. Wardlaw, V. Murray, E. Berge and G. J. Del Zoppo, "Thrombolysis for Acute Ischaemic Stroke," Cochrane Database of Systematic Reviews, Vol. 4, 2009, CD00 0213.

[99] A. Frendl and L. Csiba, "Pharmacological and Non-Pharmacological Recanalization Strategies in Acute Ischemic Stroke," Frontiers in Neurology, Vol. 2, 2011, p. 32. doi:10.3389/fneur.2011.00032

[100] S. Ansari, M. Rahman, M. F. Waters, B. L. Hoh and J. Mocco, "Recanalization Therapy for Acute Ischemic Stroke, Part 1: Surgical Embolectomy and Chemical Thrombolysis,” Neurosurgical Review, Vol. 34, No. 1, 2010, pp. 1-9. doi:10.1007/s10143-010-0293-2 